\title{
The dynamic air bubble trap reduces cerebral microembolism during cardiopulmonary bypass
}
M. Schoenburg, MD
B. Kraus, $M D^{b}$
A. Muehling, $M D^{b}$
U. Taborski, $\mathrm{MD}^{\mathrm{c}}$
H. Hofmann, $\mathrm{PhD}^{\mathrm{e}}$
G. Erhardt, $C C P^{a}$
S. Hein, $M D^{\mathrm{a}}$
M. Roth, MD
P. R. Vogt, MD, FETCS ${ }^{d}$
G. F. Karliczek, $M D^{\mathrm{b}}$
W.-P. Kloevekorn, MD ${ }^{\mathrm{a}}$

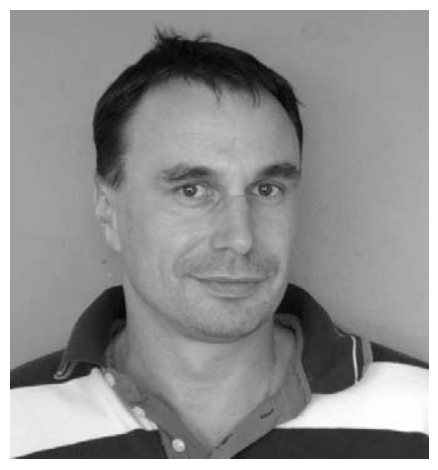

Dr Schoenburg

\footnotetext{
From the Departments of Thoracic and Cardiovascular Surgery, ${ }^{\mathrm{a}}$ Anesthesiology and Intensive Care Medicine, ${ }^{\mathrm{b}}$ and Hemostaseology and Transfusion Medicine, ${ }^{\mathrm{c}}$ Kerckhoff-Klinik, Bad Nauheim, Germany; the Department of Cardiovascular Surgery, ${ }^{\mathrm{d}}$ University of Giessen, Giessen, Germany; and the Department of Statistics, ${ }^{e}$ Iowa State University, Ames, Iowa.

Received for publication Aug 8, 2002; revisions requested Oct 10, 2002; revisions received Oct 24, 2002; accepted for publication March 13, 2003.

Address for reprints: Markus Schoenburg, MD, Department of Thoracic and Cardiovascular Surgery, Kerckhoff-Clinic Foundation, Benekestrasse 2-8, 61231 Bad Nauheim, Germany (E-mail: markus.schoenburg @ kerckhoff.med.uni-giessen.de).

J Thorac Cardiovasc Surg 2003;126: 1455-60

Copyright () 2003 by The American Association for Thoracic Surgery

0022-5223/2003\$30.00+0

doi:10.1016/S0022-5223(03)00603-2
}

Objective: Neuropsychologic disorders are common after coronary artery bypass operations. Air microbubbles are identified as a contributing factor. A dynamic bubble trap might reduce the number of gaseous microemboli.

Methods: A total of 50 patients undergoing coronary artery bypass operation were recruited for this study. In 26 patients a dynamic bubble trap was placed between the arterial filter and the aortic cannula (group 1), and in 24 patients a placebo dynamic bubble trap was used (group 2). The number of high-intensity transient signals within the proximal middle cerebral artery was continuously measured on both sides during bypass, which was separated into 4 periods: phase 1 , start of bypass until aortic clamping; phase 2, aortic clamping until rewarming; phase 3, rewarming until clamp removal; and phase 4, clamp removal until end of bypass. S100 $\beta$ values were measured before, immediately after, and 6 and 48 hours after the operation and before hospital discharge.

Results: The bubble elimination rate during bypass was $77 \%$ in group 1 and $28 \%$ in group $2(P<.0001)$. The number of high-intensity signals was lower in group 1 during phase $1(5.8 \pm 7.3$ vs $16 \pm 15.4, P<.05$ vs group 2$)$ and phase $2(6.9 \pm$ 7.3 vs $24.2 \pm 27.3, P<.05$ vs group 2 ) but not during phases 3 and 4 . Serum $\mathrm{S} 100 \beta$ values were equally increased in both groups immediately after the operation. Group 2 patients had higher $S 100 \beta$ values 6 hours after the operation and significantly higher $\mathrm{S} 100 \beta$ values 48 hours after the operation $(0.06 \pm 0.14$ vs $0.18 \pm 0.24, P=$ .0133 vs group 2). Age and $\mathrm{S} 100 \beta$ values were correlated in group 2 but not in group 1 .

Conclusion: Gaseous microemboli can be removed with a dynamic bubble trap. Subclinical cerebral injury detectable by increases of $S 100 \beta$ disappears earlier after surgical intervention.

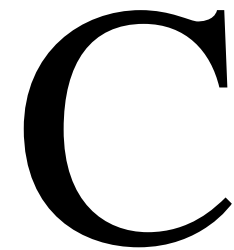
erebral injury and neuropsychologic deficits after cardiopulmonary bypass are well established in patients undergoing cardiac surgery. ${ }^{1,2}$ Macroemboli and microemboli have both been implicated in the cause of adverse cerebral outcomes. ${ }^{2-4}$ Emboli occur during extracorporeal circulation (ECC), are caused by manipulations of the aorta, ${ }^{5,6}$ and are associated with the technique of cardioplegia ${ }^{7}$ and the type of oxygenator ${ }^{8,9}$ or hardshell venous reservoir ${ }^{10}$ used. Air embolism is more common after open-chamber procedures ${ }^{11}$; however, evidence exists that the majority of microemboli during closed cardiac surgery consists of air. ${ }^{12,13}$ Trans- 


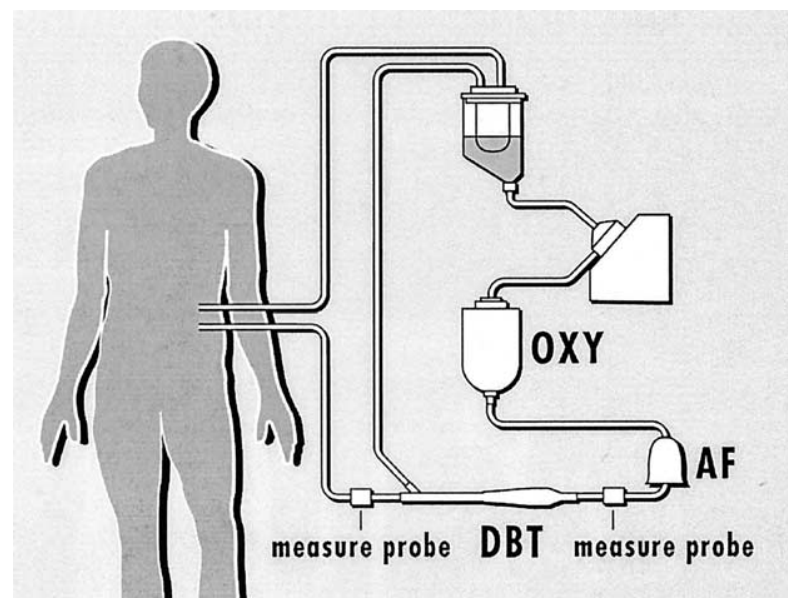

Figure 1. Cardiopulmonary bypass circuit with implementation of DBT. Oxy, Oxygenator; $A F$, conventional $40-\mu \mathrm{m}$ arterial line filter; measure probe, Doppler device. For further explanation, see text.

esophageal echocardiography, carotid ultrasonography, ${ }^{14}$ and transcranial Doppler ultrasonography were used during cardiac procedures ${ }^{6,11,15,16}$ to detect embolic signals within the aorta ${ }^{17,18}$ and the arteries supplying the brain. These embolic events could lead to increased S100 $\beta$ levels. ${ }^{19,20}$ Clinical and laboratory studies showed a significant reduction of cerebral microembolic load by using an arterial filter. ${ }^{7,21,22}$ In the present study the efficacy of a dynamic bubble trap (DBT) was investigated in patients undergoing on-pump coronary artery bypass operations.

\section{Methods \\ Patients}

Fifty patients scheduled for elective coronary artery bypass surgery were randomly assigned in a double-blind manner to one of 2 groups. In group $1(\mathrm{n}=26)$ a DBT was incorporated in the arterial line after a common $40-\mu \mathrm{m}$ arterial filter. One patient was eliminated from the study because of recurring ventricular tachycardia and fibrillation. Group $2(\mathrm{n}=24)$ was perfused with a DBT placebo, which was also placed after a $40-\mu \mathrm{m}$ arterial line filter. Exclusion criteria were as follows: age greater than 75 years; combined procedures; ejection fraction of less than 35\%; atherosclerosis of the carotid arteries; combined severe lung, renal, or cerebral diseases; drug or alcohol abuse; diabetes mellitus; emergency status; and early postoperative complications requiring prolonged artificial ventilation and sedation. The investigation interval was 10 months. The state ethics committee approved the protocol. Participating patients provided written informed consent.

\section{Transcranial Doppler Ultrasonography}

During the operation, bilateral transcranial detection of high-intensity transient signals (HITS) within the proximal middle cerebral artery was performed continuously from the beginning to end of cardiopulmonary bypass with a 2-MHz pulse-wave TCD device (CDS Neuroguard Plus, Neuroguard Inc). The flat monitoring Doppler probes were fixed before the ear above the zygomatic bone (posterior temporal window) with a head frame (Marc 500, Spencer Technologies). In group 1 middle cerebral artery insonation of both sides was successful in 25 patients, and in group 2 such insonation was successful in 21 patients. In the other 4 patients only the right medial cerebral artery was insonatable (1 in group 1 and 3 in group 2). The mean insonation depth in group 1 was $50.5 \mathrm{~mm}$ (range, 35-68 mm) on the left side and $52.3 \mathrm{~mm}$ (range, 35-68) on the right side; in group 2 the corresponding depths were $53.6 \mathrm{~mm}$ (range, 41-62 $\mathrm{mm}$ ) and 52.8 (range, 39-62 $\mathrm{mm})$, respectively.

\section{Cerebral Embolus Detection}

Automated embolus detection software (EMBOtec Version 5.2, STAC GmbH) was used. Axial extension of the sample volume was fixed at $7 \mathrm{~mm}$ (high-pass filter at $150 \mathrm{~Hz}$ ). The color-coded power spectra of the audible Doppler shift were visualized on screen (after calculation of a 128-point fast-Fourier transformation) by using an overlap of $75 \% .{ }^{23}$ Power and gain were individually adjusted to minimize the intensity of the background color spectrum and to allow the embolic signals to be completely displayed within the dynamic range of the instrument. The audible Doppler signal was recorded with a digital audio recorder (Tascam DA-30 MKII, Teac Corp) on digital audiotapes (DT 90RA, Sony Corp). Two observers manually registered microembolic signals both online and, if necessary, offline and noted corresponding surgical events and stages of the operation. The following acoustic and visual criteria for embolic signals were used: typical visible high intensity (at least $3 \mathrm{db}$ higher than that of the background blood-flow signal), typical audible sound (click, chirp, bloop), and short duration $(<200 \mathrm{~ms})$. Because the EMBOtec software has not yet been able to reliably indicate differences between artifacts and microemboli automatically, ${ }^{24}$ especially during conditions of ECC, the investigators arbitrarily rejected signals above and below the baseline at the presence of obvious artifact. The recording time was determined on the basis of the duration of bypass. Bypass time was separated into 4 periods: phase 1, start of ECC until aortic clamping; phase 2, aortic clamping until rewarming; phase 3, rewarming until clamp removal; and phase 4, clamp removal until the end of ECC.

\section{Arterial Line Embolus Detection}

A 2-channel Doppler ultrasonography device ultrasonic bubble counter (Martin Luther University, Halle, Germany) was used to detect microbubbles before and after the DBT. ${ }^{25}$ The device counts microbubbles ranging from 5 to $120 \mu \mathrm{m}$. Particulate emboli do not influence the count result. Because of minor clinical relevance, only bubbles larger than $10 \mu \mathrm{m}$ were taken into account. Hard disk registration of online data was performed for offline investigation.

\section{Dynamic Bubble Trap}

The DBT, which efficiently removes microbubbles, was developed to reduce the number of microbubbles in the arterial line. ${ }^{26,27}$ The DBT was placed in the arterial line between the arterial filter and arterial cannula (Figure 1). The shape of the DBT is tubular (Figure 2). It consists of a 3/8-in inlet, a separation chamber, a tube with a $3 / 8$-in outlet, and a site for collecting microbubbles where a recirculation line is also connected. Inside the separation chamber there is a 3-channel helix. As blood passes through the helix, 
it is converted into a rotating stream. The shape of the separation chamber causes the centrifugal forces to direct air microbubbles to the center of the flow line. After the blood passes through the tube, the process stabilizes, with the largest percentage of bubbles now in the central blood-flow line. The collection site, which is situated in the center of the distal end of the tube, diverts the central blood-flow line and returns it together with all bubbles to the cardiotomy reservoir. Because of the special hydrodynamic features of the device, the diversion of flow to the cardiotomy reservoir is constant at 400 to $450 \mathrm{~mL} / \mathrm{min}$. The efficiency of the bubble trap depends on many parameters (eg, blood viscosity, temperature, and position of a microbubble in the blood stream) but mostly on microbubble size and blood-flow velocity. The mathematic model, which was set up for the in vitro tests, showed that at least $70 \%$ of bubbles with a diameter of $15 \mu \mathrm{m}$ and at least $90 \%$ of larger bubbles $(>25 \mu \mathrm{m})$ were removed. Before clinical use, the biocompatibility of the DBT was tested in an in vitro study. ${ }^{28,29}$ There was no difference between the DBT group and the control group. The DBT placebo was a DBT without a helix but with a collection site and recirculation line to protect the blindness of the study for the investigators.

\section{Anesthesia Technique}

After premedication with flunitrazepam, total intravenous general anesthesia was induced and maintained with sufentanil and propofol. No volatile anesthetic gases were used. After relaxation with pancuronium bromide, the trachea was intubated, and controlled normocapnic ventilation with an air-oxygen mixture was started. Before or during anesthesia, standard monitors were applied, including pulse oximetry, mainstream capnometry, and peripheral and central body temperature sensors, as well as arterial and pulmonary artery catheters. Blood for arterial blood gas, electrolytes, and glucose measurement, as well as activated clotting time ascertainment, was sampled according to a standard anesthesia protocol.

\section{Protein S100ß}

Blood samples were taken before, immediately after, and 24 and 48 hours after the end of the operation, as well as before discharge from the hospital. All blood samples were cooled and centrifuged immediately and were measured by using a monoclonal 2-sided immunoradiometric assay (Sangtec 100, AB Sangtec Medical).

\section{Bypass Technique}

The DBT (HPmedica) or placebo DBT was integrated into a standard ECC tubing set (HMT Medizintechnik), which contained a 40- $\mu \mathrm{m}$ heparin-coated arterial line filter (AF 1040 Gold, Baxter). Extracorporeal perfusion was performed with a roller pump (Stoeckert Instrumente) and a hollow-fiber membrane oxygenator with venous hardshell reservoir (Biocor 200 IHS, Minntech Corp) at a nonpulsatile flow rate of $2.4 \mathrm{~L} \cdot \mathrm{min}^{-1} \cdot \mathrm{m}^{-2}$. The circuit was primed with $1600 \mathrm{~mL}$ of Ringer solution, $100 \mathrm{~mL}$ of mannitol $20 \%, 100 \mathrm{~mL}$ of sodium bicarbonate $8.4 \%, 5000$ units of heparin, and $2 \mathrm{~mL}$ of aprotinin. A standard cannulation technique was performed with a wire inlay aortic arch cannula (diameter, 0.26 in; length, 8 in; straight 3/8-in connector; Stoeckert), which was placed in the ascending aorta, as well as with a proximal and distal wire-reinforced 2-stage venous cannula (F36-32, connector 1/2 in, Medos Medizintechnik) through the right atrium after systemic

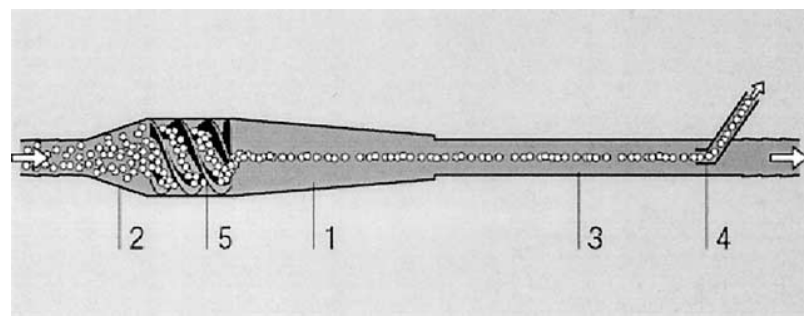

Figure 2. The DBT in detail: 1, Separation chamber; 2, 3/8-in inlet; 3, tube with 3/8-in outlet; 4, collection site; 5, 3-channel helix. For further explanation, see text.

heparinization (500 U/kg). ECC (Stoeckert Instrumente) was initiated according to the alpha-stat concept. Additional heparin was added during cardiopulmonary bypass to maintain the activated clotting time at greater than 400 seconds if necessary. The left ventricle was vented with an aortic root cannula (diameter, 14gauge; length, 5.6 in; Stoeckert Instrumente). After reaching moderate hypothermia, distal graft anastomoses were performed during aortic crossclamping. For myocardial preservation, Bretschneider Cardioplegia (Custodiol, Dr Franz Koehler Chemie, AlsbachHähnlein, Germany) was administered to achieve and sustain cardiac arrest. After the removal of the crossclamp, proximal anastomoses were made after tangential clamping of the aorta during rewarming. Weaning from ECC happened after watching the reperfusion time (one third of the crossclamp time) to recover normal myocardial function and reaching normothermic core temperature. If necessary, intravenous dopamine was infused at 3 to 5 $\mu \mathrm{g} \cdot \mathrm{kg}^{-1} \cdot \min ^{-1}$ to enhance cardiac inotropy.

\section{Statistical Analysis}

The data were collected with a computer database (SigmaPlot 4.01, SPSS Corp). Statistical analysis was performed with the DataDesk software (v6.1, Data Description Inc). All values are expressed as mean \pm SD if normally distributed or median with range. Statistical significance regarding the differences between groups was determined with a 2-sample Student $t$ test for normally distributed data or with the nonparametric Mann-Whitney rank sum test.

\section{Results}

According to the study design, one female patient of group 1 was excluded because of hemodynamic instability caused by recurring ventricular tachycardia and fibrillation. Postoperative records of all patients were uncomplicated. They could be extubated within 12 hours and left the intensive care unit after 1 day (mean intensive care unit stay, 1.04 days). Neurologic examinations of all patients on the second and third day postoperatively were normal. The biometric data of the 2 groups did not differ concerning sex and key body figures. Overall, 41 men and 8 women were included in both groups. Intraoperative data are summarized in Table 1. The bubble elimination rate of the DBT (defined as Elimination rate $=[$ Bubbles before DBT - Bubbles after $D B T) /$ Bubbles before $D B T]$ ) was $81 \%$ in group 1 and $36 \%$ in group 2. 
TABLE 1. Biometric and intraoperative data of both groups (DBT $=$ group 1 , Dummy $=$ group 2)

\begin{tabular}{|c|c|c|c|c|c|c|}
\hline Parameter & Group & Mean & SD & Median & Range & $P$ value \\
\hline \multirow[t]{2}{*}{ Age (y) } & DBT & 63.8 & 8.5 & 66.3 & 33.3 & .118 \\
\hline & Dummy & 60.1 & 7.7 & 59.9 & 32.1 & \\
\hline \multirow[t]{2}{*}{ BSA $\left(m^{2}\right)$} & DBT & 1.94 & 0.18 & 1.95 & 33.3 & .193 \\
\hline & Dummy & 2.01 & 0.2 & 1.98 & 32.1 & \\
\hline \multirow[t]{2}{*}{ ECC time (min) } & DBT & 71 & 17 & 71 & 73 & .069 \\
\hline & Dummy & 82 & 23 & 77 & 91 & \\
\hline \multirow{2}{*}{$\begin{array}{l}\text { Body temperature } \\
\quad\left({ }^{\circ} \mathrm{C}\right)\end{array}$} & $\mathrm{DBT}$ & 27 & 1.3 & 27 & 5.9 & .955 \\
\hline & Dummy & 26.9 & 1.5 & 26.6 & 7 & \\
\hline \multirow[t]{2}{*}{ No. of arterial grafts } & DBT & 1.32 & 0.748 & 1 & 3 & .167 \\
\hline & Dummy & 1.7 & 0.91 & 1.5 & 3 & \\
\hline \multirow{2}{*}{ No. of venous grafts } & DBT & 1.76 & 0.88 & 2 & 4 & .342 \\
\hline & Dummy & 2.04 & 1.16 & 2 & 4 & \\
\hline \multirow[t]{2}{*}{$\mathrm{pH}$} & DBT & 7.369 & 0.041 & 7.41 & 0.18 & .117 \\
\hline & Dummy & 7.365 & 0.086 & 7.375 & 0.44 & \\
\hline \multirow[t]{2}{*}{$\mathrm{PCO}_{2}(\mathrm{~mm} \mathrm{Hg})$} & DBT & 44.13 & 3.314 & 34 & 22 & .369 \\
\hline & Dummy & 45.13 & 4.266 & 44.5 & 13 & \\
\hline \multirow{2}{*}{$\mathrm{PO}_{2}(\mathrm{~mm} \mathrm{Hg})$} & DBT & 273 & 107 & 246 & 396 & .375 \\
\hline & Dummy & 282 & 98 & 266 & 482 & \\
\hline \multirow[t]{2}{*}{$\mathrm{Hbg}(\mathrm{g} / 100 \mathrm{~mL})$} & DBT & 7.3 & 0.72 & 7.2 & 3 & .187 \\
\hline & Dummy & 7.6 & 1.1 & 7.4 & 4.4 & \\
\hline \multirow[t]{2}{*}{ Mean AP (mm Hg) } & DBT & 40.8 & 9.7 & 38 & 28 & .372 \\
\hline & Dummy & 43.4 & 10.9 & 42 & 42 & \\
\hline \multirow[t]{2}{*}{$\mathrm{mFV}$ re $(\mathrm{cm} / \mathrm{s})$} & DBT & 28.4 & 6.2 & 28 & 22 & .377 \\
\hline & Dummy & 26.7 & 7.3 & 24 & 29 & \\
\hline \multirow[t]{2}{*}{$\mathrm{mFV}$ li $(\mathrm{cm} / \mathrm{s})$} & DBT & 28.3 & 5.9 & 28 & 22 & .756 \\
\hline & Dummy & 29 & 8.2 & 27 & 32 & \\
\hline
\end{tabular}

$B S A$, Body surface area; Bodytemp, mixed venous blood temperature after aortic crossclamping; $\mathrm{Hgb}$, hemoglobin sampled in phase 2; mean $A P$, mean arterial pressure in phase 2; $m F V$, mean flow velocity in both middle cerebral arteries.

TABLE 2. Number of bubbles in arterial line of bypass circuit

\begin{tabular}{llrrrrc}
\hline Parameter & Group & Mean & \multicolumn{1}{c}{ SD } & Median & Range & $\boldsymbol{P}$ value \\
\hline Before trap & DBT & 2825 & 3180 & 1921 & 16,442 & .435 \\
& Dummy & 2042 & 1420 & 1587 & 6114 & \\
After trap & DBT & 520 & 419 & 418 & 1550 & .001 \\
& Dummy & 1409 & 840 & 1921 & 3069 & \\
\hline
\end{tabular}

After the blood of group 1 patients passed the DBT, it contained significantly fewer bubbles than the blood of group 2 patients after passing the placebo DBT. The results of bubble detection in the arterial line are shown in Table 2. Transcranial Doppler emboli detection showed 2 to 3 times more HITS in group 2 compared with those in group 1 as far as total bypass time and different phases of bypass are concerned. These differences were significant, except in phases 3 and 4 (Table 3). Serum S100 $\beta$ values were increased in both groups at the end of the operation compared with preoperative values. A comparison between the groups at the 5 different time points showed higher $\mathrm{S} 100 \beta$ values in group 2 (Table 4). This difference is significant 48 hours postoperatively $(P=.0133)$ and has a strong tendency 6 hours postoperatively $(P=.11$; not significant but small enough to suggest a tendency). Regression analysis between age and $\mathrm{S} 100 \beta$ values showed a correlation in group $1(R=$ $0.42, P<.05)$ but not in group 2 .

\section{Discussion}

Doppler ultrasonography was used to detect cerebral emboli during coronary artery bypass surgery. ${ }^{17}$ The majority of emboli are detected after release of the aortic crossclamp and partial occlusion clamp. It has therefore been suggested that these signals mostly represent atheromatous debris rather than gaseous microbubbles. Reichenspurner and colleagues ${ }^{30}$ showed that an intra-aortic filtration system could effectively catch these particles (fibrous atheroma, medial tissue, epiaortic debris, and thrombus material).

Many studies suggest that use of a $40-\mu \mathrm{m}$ arterial filter in the arterial line of the ECC might also reduce microemboli. Our study shows that gaseous microemboli detected after the arterial filter ranged from 415 to 16,442 bubbles in the DBT group and from 453 to 6,114 bubbles in the placebo group. We conclude that this situation necessitates supplemental measures to remove this air from the extracorporeal bypass circuit.

The DBT effectively eliminated a large percentage of these microbubbles. However, after the placebo, we also measured a minor reduction of microbubbles (2042 vs 1409, 
$P>$.001). The explanation for this is that a DBT without a helix was used as the placebo. The shape of the separation chamber and the existence of the collection site and recirculation line resulted in a minor reduction of microbubbles. Even a simple tube (without a separation chamber but with a collection site and recirculation flow) would show a low efficacy. Transcranial Doppler ultrasonography in the middle cerebral arteries showed significant reductions of emboli in the DBT group compared with that seen in the placebo group, but the numbers in both groups are one decimal power lower than those in the arterial bypass line. Obviously a large number of bubbles have traveled to other parts of the body or to anterior and posterior cerebral regions.

The bubble-reducing effect of the DBT is most pronounced during phases 1 and 2. At the beginning of $\mathrm{CPB}$, the number of microbubbles per minute measured in the arterial line is high because of remaining air in the venous line at the initiation of cardiopulmonary bypass. In phase 2 the manipulation at the ascending aorta after crossclamping is relatively rare, but air introduced by means of blood sampling and drug administration by the perfusionist or over leaking purse-string sutures of the venous cannula during heart manipulation does occur far more frequently. This air can be successfully removed by the DBT.

In phases 3 and 4 embolic signals are predominantly caused by solid particles originating from manipulations of the aorta, such as partial crossclamping and removal of the aortic vent. ${ }^{3,5,30}$ Therefore the DBT has no effect on this origin of cerebral HITS.

An increased level of serum $\mathrm{S} 100 \beta$ in patients with uneventful clinical outcomes might provide evidence of subclinical injury, which could be due to diffuse microemboli and increased permeability of the blood-brain barrier, but not irreversible cerebral damage through neuronal ischemia and death. ${ }^{31}$ Lloyd and associates ${ }^{32}$ showed similar S100 $\beta$ values in 30 on-pump patients for coronary artery bypass surgery without any finding of cerebral damage. The lower air embolic load in this group, which lays bare the negative effect of age on cerebral outcome, can explain the phenomenon of age dependency of S100 $\beta$ levels in the DBT group. In the placebo group all age brackets are similarly affected by microemboli, so that the age dependency is hidden.

\section{Conclusion}

Cardiopulmonary perfusion-aided coronary artery bypass surgery allows particulate and gaseous microemboli to enter the cerebral perfusion of the patient. Gaseous microemboli can be effectively removed by the DBT. However, the DBT is not able to prevent emboli originating from the aorta itself, although it is a helpful adjunct to reduce the total embolic load to the cerebral perfusion. Subclinical cerebral injury detectable by mild increases of $S 100 \beta$ protein disappears earlier after the operation when using the DBT.
TABLE 3. Number of HITS during different phases of cardiopulmonary bypass in the right or left middle cerebral artery

\begin{tabular}{llcrrrr}
\hline Parameter & Group & Mean & SD & Median & Range & $\boldsymbol{P}$ value \\
\hline Total CPB time & DBT & 28.3 & 19.6 & 23 & 79 & $<.001$ \\
(min) & Dummy & 63.1 & 47.6 & 49 & 230 & \\
Phase 1 & DBT & 5.8 & 7.3 & 4 & 39 & $<.05$ \\
& Dummy & 16 & 15.4 & 13 & 76 & \\
Phase 2 & DBT & 6.9 & 8.2 & 4 & 44 & $<.05$ \\
& Dummy & 24.2 & 27.3 & 15 & 143 & \\
Phase 3 & DBT & 2 & 2.4 & 1 & 10 & NS \\
& Dummy & 5.8 & 5.9 & 3 & 20 & \\
Phase 4 & DBT & 13.5 & 15.5 & 7 & 60 & NS \\
& Dummy & 16.7 & 14.6 & 13 & 74 &
\end{tabular}

$C P B$, Cardiopulmonary bypass; phase 1, from beginning of cardiopulmonary bypass to aortic crossclaming; phase 2, from aortic crossclamping to begining of rewarming; phase 3, from rewarming to aortic declamping; phase 4, from aortic declamping to end of cardiopulmonary bypass; NS, not significant.

TABLE 4. S100 serum values

\begin{tabular}{lclllll}
\hline Parameter & Group & Mean & SD & Median & Range & $P$ value \\
\hline Preoperative & DBT & 0 & 0 & 0 & 0 & NS \\
\multirow{4}{*}{ End of operation } & Dummy & 0.009 & 0.0438 & 0 & 0.21 & \\
& DBT & 0.479 & 0.25 & 0.438 & 1.06 & NS \\
6 h later & Dummy & 0.502 & 0.339 & 0.415 & 1.495 & \\
& DBT & 0.057 & 0.101 & 0 & 0.24 & NS \\
48 h later & Dummy & 0.151 & 0.167 & 0.2 & 0.575 & \\
& DBT & 0.026 & 0.0831 & 0 & 0.315 & $<.05$ \\
At discharge & Dummy & 0.184 & 0.244 & 0.2 & 0.89 & \\
& DBT & 0.0362 & 0.093 & 0 & 0.315 & NS \\
& Dummy & 0.0591 & 0.103 & 0 & 0.265 & \\
& & & & & &
\end{tabular}

Serum probes were sampled preoperatively (a day before the operation), at the end of the operation, 6 and 48 hours postoperatively, and at discharge from the hospital (3-6 days postoperatively).

\section{References}

1. van Dijk D, Keizer AM, Diephuis JC, Durand C, Vos LJ, Hijman R. Neurocognitive dysfunction after coronary artery bypass surgery: a systematic review. J Thorac Cardiovasc Surg. 2000;120(4):632-9.

2. Wolman RL, Nussmeier NA, Aggarwal A, Kanchuger MS, Roach GW, Newman MF, et al. Cerebral injury after cardiac surgery: identification of a group at extraordinary risk. Multicenter Study of Perioperative Ischemia Research Group (McSPI) and the Ischemia Research Education Foundation (IREF) Investigators. Stroke. 1999;30(3):514-22.

3. Harringer W. Capture of particulate emboli during cardiac procedures in which aortic cross-clamp is used. International Council of Emboli Management Study Group. Ann Thorac Surg. 2000;70(3):1119-23.

4. Pugsley W, Klinger L, Paschalis C, Treasure T, Harrison M, Newman $\mathrm{S}$. The impact of microemboli during cardiopulmonary bypass on neuropsychological functioning. Stroke. 1994;25(7):1393-9.

5. Barbut D, Hinton RB, Szatrowski TP, Hartman GS, Bruefach M, Williams-Russo $\mathrm{P}$, et al. Cerebral emboli detected during bypass surgery are associated with clamp removal. Stroke. 1994;25(12):2398402.

6. van der Linden J, Casimir-Ahn H. When do cerebral emboli appear during open heart operations? A transcranial Doppler study. Ann Thorac Surg. 1991;51(2):237-41. 
7. Baker AJ, Naser B, Benaroia M, Mazer CD. Cerebral microemboli during coronary artery bypass using different cardioplegia techniques. Ann Thorac Surg. 1995;59(5):1187-91.

8. Mehra AP, Akins A, Maisuria A, Glenville BE. Air handling characteristics of five membrane oxygenators. Perfusion. 1994;9(5):357-62.

9. Padayachee TS, Parsons S, Theobold R, Linley J, Gosling RG, Deverall PB. The detection of microemboli in the middle cerebral artery during cardiopulmonary bypass: a transcranial Doppler ultrasound investigation using membrane and bubble oxygenators. Ann Thorac Surg. 1987;44(3):298-302.

10. Mitchell SJ, Willcox T, Gorman DF. Bubble generation and venous air filtration by hard-shell venous reservoirs: a comparative study. Perfusion. 1997;12(5):325-33.

11. Braekken SK, Russell D, Brucher R, Abdelnoor M, Svennevig JL. Cerebral microembolic signals during cardiopulmonary bypass surgery. Frequency, time of occurrence, and association with patient and surgical characteristics. Stroke. 1997;28(10):1988-92.

12. Willcox TW, Mitchell SJ, Gorman DF. Venous air in the bypass circuit: a source of arterial line emboli exacerbated by vacuum-assisted drainage. Ann Thorac Surg. 1999;68(4):1285-9.

13. Taylor RL, Borger MA, Weisel RD, Fedorko L, Feindel CM. Cerebral microemboli during cardiopulmonary bypass: increased emboli during perfusionist interventions. Ann Thorac Surg. 1999;68(1):89-93.

14. Hammon JW Jr, Stump DA, Kon ND, Cordell AR, Hudspeth AS, Oaks TE, et al. Risk factors and solutions for the development of neurobehavioral changes after coronary artery bypass grafting. Ann Thorac Surg. 1997;63(6):1613-8.

15. Clark RE, Brillman J, Davis DA, Lovell MR, Price TR, Magovern GJ. Microemboli during coronary artery bypass grafting. Genesis and effect on outcome. J Thorac Cardiovasc Surg. 1995;109(2):249-57.

16. Deverall PB, Padayachee TS, Parsons S, Theobold R, Battistessa SA. Ultrasound detection of microemboli in the middle cerebral artery during cardiopulmonary bypass surgery. Eur J Cardiothorac Surg. 1988;2(4):256-60.

17. Barbut D, Yao FS, Hager DN, Kavanaugh P, Trifiletti RR, Gold JP. Comparison of transcranial Doppler ultrasonography and transesophageal echocardiography to monitor emboli during coronary artery bypass surgery. Stroke. 1996;27(1):87-90.

18. Barbut D, Yao FS, Lo YW, Silverman R, Hager DN, Trifiletti RR, et al. Determination of size of aortic emboli and embolic load during coronary artery bypass grafting. Ann Thorac Surg. 1997;63(5):1262-7.

19. Babin-Ebell J, Misoph M, Mullges W, Neukam K, Reese J, Elert O. Intraoperative embolus formation during cardiopulmonary bypass affects the release of S100B. Thorac Cardiovasc Surg. 1999;47(3): 166-9.
20. Grocott HP, Croughwell ND, Amory DW, White WD, Kirchner JL, Newman MF. Cerebral emboli and serum S100beta during cardiac operations. Ann Thorac Surg. 1998;65(6):1645-9.

21. Padayachee TS, Parsons S, Theobold R, Gosling RG, Deverall PB. The effect of arterial filtration on reduction of gaseous microemboli in the middle cerebral artery during cardiopulmonary bypass. Ann Thorac Surg. 1988;45(6):647-9.

22. Waaben J, Sorensen HR, Andersen UL, Gefke K, Lund J, Aggestrup $\mathrm{S}$, et al. Arterial line filtration protects brain microcirculation during cardiopulmonary bypass in the pig. J Thorac Cardiovasc Surg. 1994; 107(4):1030-5.

23. Kemeny V, Droste DW, Hermes S, Nabavi DG, Schulte-Altedorneburg G, Siebler M, et al. Automatic embolus detection by a neural network. Stroke. 1999;30(4):807-10.

24. Van Zuilen EV, Mess WH, Jansen C, Van der Tweel I, Van Gijn J, Ackerstaff GA. Automatic embolus detection compared with human experts. A Doppler ultrasound study. Stroke. 1996;27(10):1840-3.

25. Jenderka K, Dietrich G, Copet U, Kopsch B, Klemnz A, Urbanek P. Detection of microbubbles in the extracorporeal circulation. IEEE Ultrasonics Proceedings. New York: 1998.

26. Schonburg M, Urbanek P, Erhardt G, Taborski U, Plechinger H, Hein $\mathrm{S}$, et al. A dynamic bubble trap reduces microbubbles during cardiopulmonary bypass: a case study. J Extra Corpor Technol. 2000;32(3): 165-9.

27. Urbanek P, Erhardt G, Taborski U, Schonburg M, Tiedtke HJ, Kloevekorn WP. Methode zur Beseitigung von Luftmikrobläschen aus arteriellem Blut während extracorporaler Zirkulation. Kardiotechnik. 1999;(4):100-2.

28. Taborski U, Urbanek P, Erhardt G, Tiedtke HJ, Schonburg M, Basser $\mathrm{S}$, et al. In vitro biocompatibility evaluation of the dynamic bubble trap. Artif Organs. 1999;23(7):663.

29. Taborski U, Urbanek P, Erhardt G, Schonburg M, Basser S, Wohlgemuth L, et al. In vitro biocompatibility evaluation of the dynamic bubble trap. Artif Organ. 2003;27(8):736-43.

30. Reichenspurner H, Navia JA, Berry G, Robbins RC, Barbut D, Gold JP, et al. Particulate emboli capture by an intra-aortic filter device during cardiac surgery. J Thorac Cardiovasc Surg. 2000;119(2):23341.

31. Ali MS, Harmer M, Vaughan R. Serum S100 protein as a marker of cerebral damage during cardiac surgery. Br J Anaesth. 2000;85(2): 287-98.

32. Lloyd CT, Ascione R, Underwood MJ, Gardner F, Black A, Angelini GD. Serum S-100 protein release and neuropsychologic outcome during coronary revascularization on the beating heart: a prospective randomized study. J Thorac Cardiovasc Surg. 2000;119(1):148-54. 